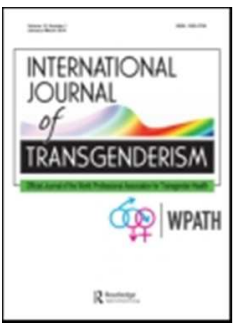

\title{
Transgender and Anxiety: A comparative study between transgender people and the general population
}

\begin{tabular}{|r|l|}
\hline Journal: & International Journal of Transgenderism \\
\hline Manuscript ID & WIJT-2016-0039.R1 \\
\hline Manuscript Type: & Original Research \\
\hline Keywords: & $\begin{array}{l}\text { transgender, anxiety, mental health, HADS, self esteem, interpersonal } \\
\text { functioning, cross-sex hormone treatment }\end{array}$ \\
\hline \multicolumn{2}{|l}{} \\
\hline
\end{tabular}

SCHOLARONE

Manuscripts

URL: http://mc.manuscriptcentral.com/wijt Email: walterbouman@doctors.org.uk 


\begin{abstract}
Background:Anxiety disorders pose serious public health problems. The data available on anxiety disorders in the transgender population is limited by the small numbers, the lack of a matched controlled population and the selection of a nonhomogenous group of transgender people.
\end{abstract}

Aims:The aims of the study were(1)To determine anxiety symptomatology (based on the HADS) in a non-treated transgender population and to compare them to a general population sample matched by age and gender;(2)To investigate the predictive role of specific variables, including experienced gender, self-esteem, victimization, social support, interpersonal functioning and cross-sex hormone use regarding levels of anxiety symptomatology;(3)To investigate differences in anxiety symptomatology between transgender people on cross-sex hormone treatment and those who are not.

Methods:A total of 913 individuals, who self-identified as transgender attending a transgender health service during a three-year period agreed participation. For the first aim of the study 592 transgender people not on treatment were matched by age and gender with 3816 people from the general population. For the second and third aim the whole transgender population was included.

Measurements:Socio-demographic variables and measures of depression and anxiety(HADS), self-esteem(RSE), victimisation(ETS), social support(MSPSS), and interpersonal functioning(IIP-32).

Results:Compared with the general population transgender people had a nearly 3fold increased risk of probable anxiety disorder(all $p<.05$ ). Low self-esteem and interpersonal functioning were found to be significant predictors of anxiety symptoms. Trans women on treatment with cross-sex hormones were found to have lower levels of anxiety disorder symptomatology.

Conclusions:Transgender people (particularly trans males) have higher levels of anxiety symptoms suggestive of possible anxiety disorders, when compared to the general population. The findings that self-esteem, interpersonal functioning and hormone treatment is associated with lower levels of anxiety symptoms indicate the need for clinical interventions targeting self-esteem and interpersonal difficulties as well as the importance of quick access to transgender health services. 
Key words: Transgender; Gender Dysphoria; anxiety; mental health; HADS; selfesteem; interpersonal functioning; cross-sex hormone treatment 


\section{Introduction}

Transgender people are a diverse population of individuals who do not present and/or identify as the gender they were assigned to at birth, either some or all of the time (Richards and Barker, 2013). Transgender identities include women and men, who feminize or masculinize their bodies with cross-sex hormone treatment (CHT) and/or gender confirming surgery (GCS), and other gender-variant individuals, who may identify and/or present in a way which is outside the gender dichotomy of man/woman (Richards et al., 2016).

Transgender people have been found to face a number of difficulties and interpersonal challenges (such as disclosing their gender identity) (Bockting and Coleman, 2016). They have been found to suffer from high levels of discrimination and victimization (Claes et al., 2015; Kattari et al., 2015; Leppel, 2016; Lombardi et al., 2001) as well as rejection from family and loved ones (Koken et al., 2009). Possibly as a consequence, many transgender people have low self-esteem (Erich et al., 2010) and high prevalence rates of mental health problems, particularly anxiety disorders and depression (Arcelus et al., 2016; Bockting et al., 2013; Claes et al., 2015; Davey et al., 2014, 2016; Dhejne et al., 2016; Heylens et al., 2014a).

Research in the transgender population pre-treatment using cross sectional data, have shown high levels of anxiety symptomatology in this population (Bockting et al., 2013; de Vries et al., 2011; Heylens et al., 2014a; Reisner et al., 2015, 2016). High levels of anxiety symptomatology are particularly prevalent in transgender people before treatment (Bergero-Miguel et al., 2016; Colizzi et al., 2013; de Vries et al., 2011; Gómez-Gil et al., 2012; Heylens et al., 2014a).

Research looking at anxiety symptoms and anxiety disorders in the transgender population have found an association with frequent experiences of discrimination in employment and housing, violence, physical and verbal abuse, societal harassment related to gender presentation, perceived need to keep one's transgender identity a secret and lack of gender confirming treatment (Bockting et al., 2013; ClementsNolle et al., 2006; McNeil et al., 2012). Some of these findings support the minority stress theory (Bockting et al., 2013; Meyer, 1995; 2003). However, these studies are 
limited by the small numbers of transgender people as well as heterogeneity of the group (for instance, people at different stages of transition).

Several studies have looked at to the role of gender confirming medical treatment (cross-sex hormone treatment (CHT) and gender affirming surgery (GAS)) in anxiety symptoms among the transgender population (Bouman et al., 2016a; Colizzi et al., 2013, 2014; Davis and Colton Meier, 2014; De Vries et al., 2014; Dhejne et al., 2016; Gomez-Gil et al., 2012; Heylens et al., 2014b; Meier et al., 2011). These studies showed that gender confirming medical treatment improves mental health, including anxiety symptomatology. However, the results are not consistent (e.g., Reisner et al., 2015) and limited by a small sample size (e.g., De Vries et al., 2014; Heylens et al., 2014b) or by the lack of matched controls (e.g., Colizzi et al., 2013, 2014; Davis and Colton Meier, 2014; Gomez-Gil et al., 2012).

This study addresses the aforementioned limitations of a small sample size, a lack of homogeneity and a matched control group. The current study investigates the prevalence of possible or probable anxiety disorder in a large cohort of adult transgender people, who seek treatment at a national transgender health service; and the study compares this large cohort of adult transgender people to general population data matched by age and gender (experienced gender).

This study has several aims. Firstly, to determine the levels of anxiety symptomatology suggesting possible and probable anxiety disorder in non-treated transgender people and to compare them with a cisgender (cis) population matched by age and gender. Secondly, to investigate the predictive role for anxiety disorders (possible and probable) of specific variables known to be associated with anxiety symptoms in the cisgender and transgender population such as age, gender, selfesteem, social support, interpersonal functioning and victimisation and the use of CHT in transgender people (Bouman et al., 2016a; Claes et al., 2015; Colizzi et al., 2014; Davey et al., 2014, 2015; Gomez-Gil et al., 2012; Kessler et al., 2005a; Kessler et al., 2005b; McLean et al., 2011; Meier et al., 2011). Finally, to investigate differences in anxiety scores between transgender people on cross-sex hormone treatment $(\mathrm{CHT})$ with those not on cross-sex hormone treatment (non-CHT). For the 
last two aims the whole population of transgender people (on CHT and not on CHT) will be selected.

Based on the literature regarding anxiety and transgender people, it was hypothesized that levels of anxiety will be higher in the transgender population compared to the general population, and associated with psychopathology, decreased self-esteem and social support, discrimination, lower levels of interpersonal functioning and lack of $\mathrm{CHT}$ treatment. There is no clear hypothesis regarding the relationship between gender and anxiety symptoms. Studies in the general population suggest that cisgender women present with higher levels of anxiety symptoms than cisgender men, which may suggest that trans women present with higher anxiety symptoms too. There is, however, also the possibility that genetic factors play a role in the aetiology of anxiety disorders, and consequently a predisposition to develop anxiety disorders may relate to one's assigned gender at birth.

\section{Methods}

Participants and Procedures

\section{Transgender participants}

The sample consisted of all individuals who self-identify as transgender and attended for an assessment to a national transgender health service in $X$ during a 3-year period, between November 2012 and October 2015. For the first aim of the study only individuals not on treatment with cross-sex hormones (non-CHT) before assessment will be selected in order to have a homogeneous group.

Following assessment, the transgender person is considered for entry into the treatment programme. Treatment, including $\mathrm{CHT}$ and GAS is free at the point of access in the National Health Service (NHS) in the United Kingdom for all citizens. Patients will usually start $\mathrm{CHT}$, following informed consent, if there are no physical contraindications. Chest reconstructive surgery is generally available to trans men after being on testosterone treatment for a minimum of 6 months. Genital reconstructive surgeries are generally available to transgender people after being in the treatment programme for a minimum of 12 months. We acknowledge that not all transgender people wish to take cross-sex hormones or undergo gender confirming surgeries; a growing number of transgender people express a wish for partial 
treatment (Beek et al., 2015). Once transgender people have undergone their desired treatment, follow-up care can be organised at the service, if they wish (Wylie et al., 2014).

Prior to the clinical assessment every patient was invited to participate in the study, and if agreed to complete a battery of questionnaires. The study received ethical approval from the NHS Ethics committee and from the Research and Development Department from X in line with Health Research Authority guidance (HRA, 2013).

\section{Control group}

A total of 3816 adults from the general population with an age range of 16-92 who participated in another study (Crawford et al., 2009) was used as controls and matched by age and gender. These samples were recruited between 2006 and 2009. In order to increase the normative data, a broad representation of the general adult UK population was selected, in terms of the age, education, and gender (although, in most cases, females were over sampled). The recruitment process included a variety of sources such as large and small businesses, public service organizations, community centres, and recreational groups. The majority of participants were recruited from urban/ suburban locations, although rural/semi-rural people were also represented. As per the transgender group, participants were invited to complete the Hospital Anxiety and Depression Scale (Zigmond \& Snaith, 1983) and place them in a sealed envelope. The questionnaires were filled out anonymously. The combined refusal/non-return rates ranged from approximately $17 \%$ to $21 \%$.

Ethical approval was obtained from the Psychology Ethics Committee of the University of $X$.

\section{Main Outcome Measures}

The Hospital Anxiety and Depression Scale (HADS) (Zigmond \& Snaith, 1983) is a 14-item self-report screening scale that was originally developed to indicate the possible presence of anxiety and depression states in the setting of a medical nonpsychiatric outpatient clinic. HADS consists of two subscales, HAD-Anxiety (HAD-A) and HAD-Depression (HAD-D). For this study only the subscale of anxiety will be 
used. This subscale has seven items, rated on a 4-point Likert scale (ranging from, as much as I always do (0); not quite so much (1); definitely not so much (2); to not at all (3)), indicating symptoms of anxiety during the preceding week. A score of 0-7 on either scale is regarding as being in the normal range (no symptoms), a score of 8-10 is suggestive of the presence of an anxiety disorder (possible symptoms), and a score of 11 or higher indicates the probable presence of an anxiety disorder (symptoms) of the respective state. Maximum subscales scores are 21 for anxiety. The HADS was found to perform well in assessing the symptom severity and caseness of anxiety disorders in both somatic, psychiatric and primary care patients and in the general population (Bjelland et al., 2002) and it has been previously used with transgender individuals (Bouman et al., 2016a; Gomez-Gil et al., 2012). A number of researchers have explored HADS data to establish the cut-off points for caseness of anxiety. Bjelland et al. (2002) through a systematic review of a large number of studies identified a cut-off point of $8 / 21$ for anxiety. For anxiety (HADS-A) this gave a specificity of 0.78 and a sensitivity of 0.9 . In this study, the Cronbach's alpha was 0.68 for the anxiety scale.

The Rosenberg Self-Esteem Scale (RSE) (Rosenberg, 1965) is a self-report measure of global self-esteem. Items are rated on a 4-point rating scale ranging from 0 ('Strongly disagree') to 3 ('Strongly agree'). Its total score is calculated by summing the item scores with higher scores indicating higher self-esteem. The RSE has been empirically validated and administered previously to transgender individuals (Arcelus et al., 2016; Vocks et al., 2009). In this study the Cronbach's alpha was 0.91.

The Experiences of Transgender Phobia Scale (Lombardi et al., 2001) assesses experiences of discrimination or victimization on the basis of gender identity or gender presentation. The questionnaire was based on the Transgender Violence Study and measured people's lifetime experiences of violence and harassment and experiences of any form of economic discrimination as a result of being transgender (e.g., verbal abuse, physical abuse, fired from a job, problems getting a job, and problems getting health or medical services due to gender identity or presentation). All five items are to be rated on a four-point Likert scale ranging from 0 ('never") to 3 ('several times'). This scale has been previously used with transgender individuals 
(Arcelus et al., 2016; Bouman et al., 2016a,b; Claes et al., 2015). In this study the Cronbach's alpha was 0.59 .

The Multidimensional Scale of Perceived Social Support (MSPSS) (Zimet et al., 1990 ) is a 12-item, self-report scale designed to tap social support from family, friends, and significant others. Items are rated on a 7-point Likert scale ranging from 1 ('very strongly agree') to 7 ('very strongly disagree'). The instrument includes three subscales to address these three types of support (family, friends, significant others). The mean total and subscale scores range from 1 to 7 , and a higher score indicates greater perceived social support. This scale has recently been used in transgender populations (Boza et al., 2014; Davey et al., 2014, 2016). In this study the Cronbach's alpha was 0.89 for the total scale.

The Inventory of Interpersonal Problems (IIP-32) (Barkham et al., 1996) measures interpersonal difficulties. It consists of 32 items to be rated on a 5-point Likert scale ranging from 0 ('Not at all') to 4 ('Extremely'). There are eight subscales of interpersonal problems: Hard to be Assertive, Hard to be Sociable, Hard to be Supportive, Hard to be Involved, Too Dependent, Too Caring, Too Aggressive, and Too Open. A total mean score provides a global measure of interpersonal distress. Higher subscale scores indicate greater interpersonal difficulties. The IIP-32 is a shortened version of the original IIP, yet the psychometric properties are retained; a confirmatory factor analysis demonstrated high reliability with alpha coefficients of 0.70 to 0.88 (Barkham et al., 1996). The IIP-32 has been used successfully in both non-clinical (Berry et al., 2006) and clinical samples (Bouman et al., 2016b; Davey et al., 2015). In this study the Cronbach's alpha was 0.87 for the total scale.

\section{Data Analysis}

All quantitative data analyses were performed by means of SPSS 22 (IBM, 2013). First descriptive statistics were applied. For the first aim, only transgender people will be included in order to have a homogenous group. As per the authors advice based on the HADS three categories will be developed: 1) people with no anxiety disorder, 2) people with symptoms suggesting of a possible anxiety disorder and, 3) people with symptoms suggesting a probable anxiety disorder. We used the Chi-Square Test Statistic to calculate the association between the three levels of anxiety 
symptomatology and the participant status (transgender and controls) for the total group and for males/females separately. For the second aim, the prediction of the presence/absence of an anxiety disorder based on self-esteem, social support, interpersonal functioning and victimization and the use of $\mathrm{CHT}$ in transgender people controlled for gender and age, we performed a hierarchical regression analysis, with the presence/absence of the anxiety disorder as a dependent variable (dummy), age and gender (step 1) as control variables and the other variables (step 2) as predictors. For the third aim, the association between the presence/absence of an anxiety disorder and the use/not use of $\mathrm{CHT}$, we calculated the Chi Square Test Statistic for the total group, and males/females separately. The level of significance used was $p<0.05$.

\section{Results}

Socio-demographic characteristics of the whole sample regarding

During the recruitment period of 3 years 913 individuals who fulfilled the inclusion criteria agreed to participate. Twenty-five individuals (2.6\%) did not agree participation, which gives a response rate of $97.4 \%$. The age range of the participants was 15-79 years with a mean age of 30.4 years $(S D=13.9) ; 582(63.7 \%)$ patients identified themselves as trans females (assigned male at birth) and 331 $(36.3 \%)$ as trans males (assigned female at birth). Of the total sample of 913 transgender people $640(70,1 \%)$ were not on cross-sex hormone treatment, 259 $(28.4 \%)$ were on $\mathrm{CHT}$, whilst for 14 patients $(1.5 \%)$ this information was not available and they were removed for further analyses.

Comparative analyses between transgender people not on CHT and controls.

For the first aim of the study only people not on CHT were selected $(n=640)$. Of the 640 patients in the non-CHT group the age range was 16-79 years with a mean age of 28.6 years $(S D=12.8) ; 393(61.4 \%)$ patients identified as trans females (assigned male at birth) and 247 (38.6\%) were trans males (assigned female at birth). This group was matched by age and experienced gender with the control group. Of the 640 patients in the non-CHT group 48 (7.5\%) could not be matched due to insufficient numbers for that age in the control data. This group consisted of 19 trans females and 28 trans males aged 17 and 18 with an average age of 17.3 years (SD= 0.48). The remaining sample of 592 non- $\mathrm{CHT}$ patients were block matched with the 
control population data base. This meant that for the first aim, a total of 1184 participants were selected, 592 in each group.

Out of the 592 transgender and cisgender participants, $218(36.8 \%)$ were trans and cis females and 374 (63.2\%) were trans and cis males respectively. As Table 1 shows the control group were significantly more prevalent in the category of 'No Anxiety Disorder' compared to the transgender group, whereas the transgender people were significantly more prevalent in the categories 'Possible and Probable Anxiety Disorder' compared to the control group. This difference was statistically significant $\left[\mathrm{X}^{2}{ }_{(2)}=148.997, p<.001\right]$. When comparing trans with cis men $\left[\mathrm{X}^{2}{ }_{(2)}=\right.$ $128,521, p<.001]$ and trans with cis women $\left[\mathrm{X}^{2}(2)=21,443, p<.001\right]$, the difference was still statistically significant.

(Insert Table 1. about here)

Predictors of anxiety disorders (probable and possible) among the whole transgender population

In order to analyze the predictors of anxiety in the transgender population, the whole group of 913 transgender people (excluding the 14 people without information regarding $\mathrm{CHT}$ ), were included (giving a total of 899 individuals). Those in the category of probable and possible anxiety symptoms were grouped together into one category (anxiety disorder). A linear hierarchical regression analysis with the presence or absence of anxiety disorder as dependent variable, age and gender as control variables, and self-esteem, social support, interpersonal functioning and victimization and presence and absence of $\mathrm{CHT}$ as independent variables was performed. The results showed that low self-esteem and interpersonal problems were the only significant predictors for a transgender person attending transgender health services to suffer from a possible and probable anxiety disorder. Interpersonal functioning was a stronger predictor (See Table 2).

(Insert Table 2. about here) 
Comparison between people on $\mathrm{CHT}$ and those not on $\mathrm{CHT}$

Analyses comparing transgender people on $\mathrm{CHT}$ with those not on $\mathrm{CHT}$ found a statistically significant difference between both groups with more transgender people using $\mathrm{CHT}$ in the category of no anxiety disorder compared to those on not on $\mathrm{CHT}$ $\left[X^{2}{ }_{(1)}=20,266, p<.001\right]$. The latter group is more prevalent in the category anxiety disorder (see Table 3.). As the use of $\mathrm{CHT}$ was more prevalent among trans females and anxiety symptoms were more prevalent among trans men the same analyses were performed according to gender. The new analyses showed that for trans females being on $\mathrm{CHT}$ was associated with less anxiety disorder as there were more trans females not on CHT in the category of anxiety disorders when compared to trans females on $\mathrm{CHT}\left[\mathrm{X}^{2}{ }_{(1)}=21,802, p<.001\right]$. This was not the case for trans males $\left[X^{2}(1)=1,379, p<.240\right]$.

(Insert Table 3 about here)

\section{Discussion}

Anxiety disorders are the most common mental disorders, with a reported 12-month prevalence of $18.1 \%$ and a lifetime prevalence of $28.8 \%$ (Kessler et al., 2005a; Kessler et al., 2005b). Moreover, women are significantly more likely than men to develop an anxiety disorder throughout the lifespan (McLean et al., 2011). Owing to their high prevalence, combined with an often early onset and chronic course, anxiety disorders are the second most important cause of disability worldwide within the group of mental and behavioural disorders (Whiteford et al., 2013; de Vries et al., 2016). This study found high rates of possible (32.8\%) and probable (36.0\%) current anxiety disorder in untreated transgender people attending a transgender health service. Compared with a cisgender matched control group from the general population, transgender people had an almost 3-fold increased risk of probable anxiety disorder. Trans males showed higher rates of possible and probable anxiety disorder $(71.1 \%)$ than trans females $(59.8 \%)$, which would be in keeping with the 
literature on gender differences in anxiety disorders, if the pattern of birth gender is followed (McLean et al., 2011). Studies looking as to why anxiety symptoms are more prevalent among individuals whose gender is assigned female at birth, suggest that differences in neurobiological make-up may account for these differences. The brain system involved in the fight-or-flight response is activated more readily in female-assigned-at-birth individuals and stays activated longer than male-assignedat-birth individuals, partly as a result of the action of estrogen and progesterone. The neurotransmitter serotonin may also play a role in responsiveness to stress and anxiety. Some evidence suggests that the brain of individuals, whose sex is assigned female at birth does not process serotonin as quickly as their male counterparts. Recent research has also found that female-assigned-at-birth individuals are more sensitive to low levels of corticotropin-releasing factor (CRF), a hormone that organizes stress responses in mammals, making them twice as vulnerable as their male-assigned-at-birth counterparts to stress-related disorders (Bangasser et al., 2016).

This study found low self-esteem and interpersonal functioning to be predictors of anxiety disorder, which highlights the importance of psychological intervention and support in this vulnerable group. Psychological treatment aiming at improving selfesteem and interpersonal functioning may help transgender individuals at risk of developing anxiety disorder when going through the transitional process. Various psychological treatments have proven efficacious in increasing self-esteem (Morton et al., 2012; Fennel, 2006; Rigby and Waite, 2007). Similarly, interpersonal psychotherapy (IPT) has been found efficacious in reducing interpersonal problems. As IPT has been successfully used in various populations (e.g., Arcelus et al., 2011; Hara et al., 2000; Mufson et al., 2013), it could be adapted for use within the transgender population (Budge, 2013). For those transgender patients who meet a diagnosis of anxiety disorder current treatment approaches apply, including consideration of pharmacotherapy and/or psychological treatment (Baldwin et al., 2014; lacoviello \& Charney, 2015).

Further findings confirmed the benefits of cross-sex hormone treatment, particularly for trans women on $\mathrm{CHT}$, as they were significantly more prevalent in the category no anxiety disorder compared to those who do not use cross-sex hormones. That these findings do not apply to trans men is surprising, and certainly do not reflect our clinical experience. One explanation may be that the higher risk of developing 
anxiety disorder for people whose sex is female assigned at birth offsets the positive psychological benefits of CHT in trans men. This specific area needs further study. The findings confirm existing research (Gomez-Gil et al., 2012; Colizzi et al., 2014; De Vries et al., 2014; Heylens et al., 2014b; Bouman et al., 2016) and add further weight to the rationale of early treatment for gender dysphoria. In many countries, long waiting lists and lack of clinical services for transgender people combined with overly prescriptive pathways to access CHT in Standards of Care (Coleman et al., 2012; Wylie et al., 2014) continue to be significant barriers to treatment for transgender people. Moreover, these barriers to access treatment are likely to further increase the rate of anxiety disorders; also, they tend to lead to selfprescribing via the Internet without medical supervision (Mepham et al., 2014).

There are aspects of the study that warrant attention in relation to limitation of the results. First, the study is limited by selecting a specific population of treatment seeking individuals and doing so in a country in which the waiting list for a first appointment at a transgender health service is long. Hence, the results may not be generalizable to other transgender people who do not access clinical services or to other countries with different healthcare systems. Second, the research makes use of self-reported questionnaires, and although most are adequately validated and have been used in transgender populations, future research could use structured clinical interviews to differentiate the clinical group from those with and without anxiety disorder and other psychiatric morbidity. Furthermore, a limitation of the study is the cross-sectional nature of the data. From the current data, it is not possible to determine whether the psychological benefits associated with the use of $\mathrm{CHT}$ predate or are a consequence of disclosure of experienced gender and/or social gender role transition. It also may be that those with better self-esteem and less psychopathology feel more confident to commence treatment without medical advice. They may use the support and advice of their friends who also may be taking $\mathrm{CHT}$. The lack of information regarding the gender identity of the control group used, makes it impossible to generalize the results to the transgender population, as some of people in control group may also identify as transgender. This information was not asked, although, given the low prevalence the impact on the final results is likely to be negligible (Arcelus et al., 2015). Many studies in the field of transgender health have included people fulfilling a diagnosis as per the ICD or DSM (e.g., Colizzi et al., 
2013; de Vries et al., 2011; Gómez-Gil et al., 2012; Heylens et al., 2014ª) as well as relying on self-identification regarding one's gender (e.g., Bockting et al., 2013; Davis \& Colton Meier, 2014; Reisner et al., 2016; Warren et al., 2016). This study has not used a diagnosis to classify people, but selected a population of people who selfidentify as transgender and access transgender health services for treatment. It can be argued that the population selected in this study may be slightly different to the one fulfilling diagnostic criteria, although this is not our clinical impression, but we do want to acknowledge this difference. A final note on the generalizability of the findings is that there are particularities with regards to medical treatment and legislation for transgender person people in the UK. For example, some aspects of gender reassignment treatment (e.g. CHT and/or GCS) are available through the NHS free at the point of access, and the Gender Recognition Act 2004 provides legal recognition of a trans individual's experienced gender. In addition, the Sex Discrimination (Gender Reassignment) Regulations Act 1999, and its amendment in 2008, deemed it unlawful to discriminate on the basis of gender reassignment within employment and vocational training, as well as within the provision of goods, facilities, and services. Consequently, the experience of living as a transgender person in the United Kingdom may be different from living as a transgender person in other countries (Davey et al., 2015).

In spite of the above limitations the strength of the paper is the large group of transgender and control group involved, making this one of the largest studies in this field. The study is also strengthened by the matching of groups (transgender and controls and transgender on CHT and not on CHT). The lack of matching between groups in the transgender literature has been criticized previously (Dhejne et al., 2016).

Notwithstanding the aforementioned limitations, this study clearly shows that treatment-seeking transgender individuals have a high prevalence rate of possible and probable anxiety disorder compared to the general population. Having an experienced male gender, low self esteem, interpersonal problems and lack of crosssex hormone treatment are specifically associated with an increased likelihood of coexisting anxiety disorder in transgender people, having low self esteem and interpersonal problems being the main predictors for anxiety. Mental health services 
should take heed of these findings to improve outcomes in this vulnerable group of individuals.

\section{Disclosure of interest}

The authors declare that they have no conflicts of interest concerning this article.

\section{References}

Arcelus, J., Bouman, W.P., Witcomb, G.L., Van den Noortgate, W., Claes, L., \& Fernandez-Aranda, F. (2015). Prevalence of Transsexualism: A systematic review and meta-analysis. European Psychiatry, 30(6), 807-815.

Arcelus, J., Claes, L., Witcomb, G.L., Marshall, E., Bouman, W.P. (2016). Risk Factors for Non Suicidal Self Injury among Trans Youth. Journal of Sexual Medicine, 13(3), 402-412.

Arcelus, J., Whight, D., \& Haslam, M. (2011). Interpersonal problems in people with bulimia nervosa and the role of interpersonal psychotherapy. In P. Hay (Ed.), New insights into the prevention and treatment of bulimia nervosa (pp. 3-12). Rijeka: InTech.

Baldwin, D.S., Anderson, I.M., Nutt, D.J., Allgulander, C., Bandelow, B., den Boer J.A., Christmas, D.M., Davies, S., Fineberg, N., Lidbetter, N. (2014). Evidence-based pharmacological treatment of anxiety disorders, post-traumatic stress disorder and obsessive-compulsive disorder: a revision of the 2005 guidelines from the British Association for Psychopharmacology. Journal of Psychopharmacology, 28, 403-439. Bangasser, D.A., Wiersielis, K.R., \& Khantsis, S. (2016). Sex differences in the locus coeruleus-norepinephrine system and its regulation by stress. Brain Research, 1641, 177-188.

Barkham, M., Hardy, G.E., \& Startup, M. (1996). The IIP-32: a short version of the Inventory of Interpersonal Problems. British Journal of Clinical Psychology, 35, 2135.

Beek, T., Kreukels, B.P.C., Cohen-Kettenis, P.T., \& Steensma, T.D. (2015). Partial gender request and underlying motives of applicants for gender affirming interventions. Journal of Sexual Medicine, 12, 2201-2205.

Bergero-Miguel, T., García-Encinas, M.A., Villena-Jimena, A., Pérez-Costillas, L., Sánchez-Alvarez, N., de Diego-Otero, Y., \& Guzman-Parra, J. (2016). Gender 
dysphoria and social anxiety: An exploratory study in Spain. Journal of Sexual Medicine, 13, 1270-1278.

Berry, K., Wearden, A., Barrowclough, C., \& Liversidge, T. (2006). Attachment styles, interpersonal relationships and psychotic phenomena in a non-clinical student sample. Personality and Individual Differences, 41, 707-718.

Bjelland, I., Dahl, A.A., \& Neckelmann, T.T. (2002). The validity of the Hospital Anxiety and Depression Scale. An updated literature review. Journal of Psychosomatic Research, 52, 69-77.

Bockting, W.O., Miner, M.H., Swinburne Romine, R.E., Hamilton, A., Coleman, E. (2013). Stigma, mental health, and resilience in an online sample of the US transgender population. American Journal of Public Health, 103, 943-951. Bockting, W.O. \& Coleman, E. (2016). Developmental stages of the transgender coming-out process. Chapter 9. In: Ettner, R., Monstrey, S., \& Coleman, E. (eds.).

Principles of Transgender Medicine and Surgery. New York, NY: Routledge. Bouman, W.P., Claes, L., Marshall, E., Pinner, G.T., Longworth, J., Maddox, V., Witcomb, G., Jimenez-Murcia, S., Fernandez-Aranda, F., \& Arcelus, J. (2016a). Socio-demographic variables, Clinical Features and the Role of Pre-assessment Cross-Sex Hormones in older trans people. Journal of Sexual Medicine,13(4), 711719.

Bouman, W.P., Davey, A., Meyer, C., Witcomb, G.L. \& Arcelus, J. (2016b). Predictors of psychological well-being among trans individuals. Sexual and Relationship Therapy, 31(3), 357-373.

Boza, C. \& Perry, K.N. (2014). Gender-related victimization, perceived social support, and predictors of depression among transgender Australians. International Journal of Transgenderism,15, 35-52.

Budge, S. L. (2013). Interpersonal psychotherapy with transgender clients. Psychotherapy, 50(3), 356-359. doi:10.1037/a0032194 Claes, L., Bouman, W.P., Witcomb, G., Thurston, M., Fernandez-Aranda, F., Arcelus, J. (2015). Non-Suicidal Self Injury in Transsexualism: Associations with Psychological Symptoms, Victimization, Interpersonal Functioning and Perceived Social Support. Journal of Sexual Medicine, 12, 168-179. 
Clements-Nolle, K., Marx, R., \& Katz, M. (2006). Attempted suicide among transgender persons: The influence of genderbased discrimination and victimization. Journal of Homosexuality, 51, 53-69. doi:10.1300/J082v51n03 04 Coleman, E., Bockting, W., Botzer, M., Cohen-Kettenis, P., De Cuypere, G., Feldman, J., Fraser, L., ..... Zucker, K. (2012). Standards of care for the health of transsexual, transgender, and gender-nonconforming people, version 7. International Journal of Transgenderism, 13, 165-232.

Colizzi, M., Costa, R., Todarello, O. (2014). Transsexual Patients' psychiatric comorbidity and positive effect of cross-sex hormonal treatment on mental health. Psychoneuroendocrinology, 39, 65-73.

Crawford, J. R., Henry, J. D., Crombie, C. and Taylor, E. P. (2001). Normative data for the HADS from a large non-clinical sample. British Journal of Clinical Psychology, 40, 429-434.

Crawford, J. R., Garthwaite, P. H., Lawrie, C. J., Henry, J. D., MacDonald, M. A., Sutherland, J., \& Sinha, P. (2009). A convenient method of obtaining percentile norms and accompanying interval estimates for self-report mood scales (DASS, DASS-21, HADS, PANAS, and sAD). British Journal of Clinical Psychology, 48, 163180.

Davey, A., Arcelus, J., Meyer, C., \& Bouman, W.P. (2016). Self-injury among trans individuals in transition and matched controls: Prevalence and associated factors. Health \& Social Care in the Community, 24, 485-494.

Davey, A., Bouman, W.P., Arcelus, J., Meyer, C. (2014). Social support and psychological wellbeing: A comparison of patients with gender dysphoria and matched controls. Journal of Sexual Medicine, 11, 2976-85.

Davey, A., Bouman, W.P., Arcelus, J., Meyer, C. (2015). Interpersonal functioning among individuals with gender dysphoria. Journal of Clinical Psychology, 71, 11731185.

Davis, S.A. and Colton Meier, S. (2014). Effects of testosterone treatment and chest reconstruction surgery on mental health and sexuality in female-to-male transgender people. International Journal of Sexual Health, 26, 113-128.

De Vries, A.L.C., Doreleijers, T.A.H., Steensma, T.D., \& Cohen-Kettenis, P.T. (2011).Psychiatric comorbidity in gender dysphoric adolescents. Journal of Child Psychology and Psychiatry, 52, 1195-1202. 
De Vries, A.L.C., McGuire, J.K., Steensma, T.D., Wagenaar, E.C.F., Doreleijers, T.A.H., Cohen-Kettenis, P.T. (2014). Young adult psychological outcome after puberty suppression and gender reassignment. Pediatrics, 134, 696-704.

De Vries, Y.A., De Jonge, P., Van den Heuvel, E., Turner, E.H., Roest, A.M. (2016). Influence of baseline severity on antidepressant efficacy for anxiety disorders: metaanalysis and meta-regression. British Journal of Psychiatry, 208, 515-521.

Dhejne, C., Van Vlerken, R., Heylens, G., \& Arcelus, J. (2016). Mental health and gender dysphoria: A review of the literature. International Review of Psychiatry, 28(1), 44-57.

Erich, S., Tittsworth, J., Kerstein, A.S. (2010). An examination and comparison of transsexuals of color and their white counterparts regarding personal well-being and support networks. Journal of GLBT Family Studies, 6, 25-39.

Fennell, M. (2006). Overcoming low self-esteem: Self-help program. London: Constable and Robinson 2006.

Gómez-Gil, E., Zubiaurre-Elorza, L., Esteva, I., Guillamon, A., Godas, T., Cruz Almaraz, M., Halperin, I., Salamero, M. (2012). Hormone-treated transsexual report less social distress, anxiety, and depression. Psychoneuroendocrinology, 37, 662670.

Hara, M. W. O., Stuart, S., Gorman, L. L., \& Wenzel, A. (2000). Efficacy of interpersonal psychotherapy for postpartum depression. Archives of General Psychiatry, 57, 1039-1045.

Health Research Authority (HRA) (2013). Guidance for NHS Research Studies. London: Health Research Authority.

Heylens, G., Elaut, E., Kreukels, B.P.C., Paap, M.C.S., Cerwenka, S., RichterAppelt, H., Cohen-Kettenis, P.T., Haraldsen, I.R., De Cuypere, G. (2014a).

Psychiatric characteristics in transsexual individuals: multicenter study in four European countries. British Journal of Psychiatry, 204, 151-156.

Heylens, G., Verroken, C., De Cock, S., T'Sjoen, G., and De Cuypere, G. (2014b). Effects of Different Steps in Gender Reassignment Therapy on Psychopathology: A Prospective Study of Persons with a Gender Identity Disorder. Journal of Sexual Medicine,11, 119-126. doi: 10.1111/jsm.12363

Hosmer DW and Lemeshow S. (2004). Logistic regression for matched case-control studies. Applied logistic regression. Chapter 7. Pp 223-259. Second edition.

Danversa, MA: John Wiley \& Sons. 
lacoviello, B.M. \& Charney, D.S. (2015). Developing cognitive-emotional training exercises as interventions for mood and anxiety disorders. European Psychiatry, 30, 75-81.

IBM Corporation (2013). IBM SPSS Statistics for Windows. Version 22.0. Armonk, NY: IBM Corporation.

Kattari, S.K., Walls, N.E., Whitfield, D.L., \& Langenderfer-Magruder, L. (2015). Racial and ethnic differences in experiences of discrimination in accessing health services among transgender people in the United States. International Journal of Transgenderism, 16, 68-79.

Kessler, R.C., Chiu, W.T., Demler, O., Walters, E.E. (2005a). Prevalence, severity, and comorbidity of 12-month DSM-IV disorders in the National Comorbidity Survey Replication. Archives of General Psychiatry, 62, 617-627.

Kessler, R.C., Berglund, P.A., Demler, O., Jin, R., Merikangas, K.R., Walters, E.E. (2005b). Lifetime prevalence and age-of-onset disributions of DSM-IV disorders in the National Comorbidity Survey Replication. Archives of General Psychiatry, 62, 593-603.

Koken, J., Bimbi, D.S., Parsons, J.T. (2009). Experiences of familial acceptancerejection among transwomen of color. Journal of Family Psychology, 23, 853-860. doi:10.1037/a0017198

Leppel, K. (2016). The Labor Force Status of Transgender Men and Women. International Journal of Transgenderism, $17(3+4)$, Lombardi, E.L., Wilchins, R.A., Priesing, D., Malouf, D. (2001). Gender Violence. Journal of Homosexuality, 42, 89-101.

Marshall, E., Claes, L., Bouman, W.P., Witcomb, G.L., Arcelus, J. (2016). NonSuicidal Self-Injury and Suicidality in Trans People: A Systematic Review of the Literature. International Review of Psychiatry, 28, 58-69.

McLean, C.P., Asnaani, A., Litz, B.T., Hofmann, S.G. (2011). Gender differences in anxiety disorders: prevalence, course of illness, comorbidity and burden of illness. Journal of Psychiatric Research, 45, 1027-1035.

McNeil, J., Bailey, L., Ellis, S., Morton, J., Regan, M. (2012). Trans mental health and emotional wellbeing study. Edinburgh: Scottish Transgender Alliance. 
Meier, S., Fitzgerald, K., Pardo, S., \& Babcock, J. (2011). The effects of hormonal gender affirmation treatment on mental health in female-to-male transsexuals. Journal of Gay and Lesbian Mental Health, 15, 281-299. Mepham, N.J., Bouman, W.P., Arcelus, J., Hayter, M., Wylie, K.R. (2014). People with gender dysphoria who self prescribe cross sex hormones: prevalence, sources and side effects knowledge. Journal of Sexual Medicine, 11, 2995-3001. Meyer, I.H. (1995). Minority stress and mental health in gay men. Journal of Health and Social Behavior, 36, 38-56.

Meyer, I.H. (2003). Prejudice, social stress, and mental health in lesbian, gay and bisexual populations: Conceptual issues and research evidence. Psychological Bulletin, 129, 674-697.

Morton, L., Roach, L., Reid, H., Stewart, S.H. (2012). An Evaluation of a CBT Group for Women with Low Self-Esteem. Behavioural and Cognitive Psychotherapy, 40, 221-225.

Mufson, L., Weissman, M., Moreau, D., \& Garfinkel, R. (2013). Efficacy of interpersonal psychotherapy for depressed adolescents. Archives of General Psychiatry, 56, 573-579.

Reisner, S.L., Vetters, R., Leclerc, M, Zaslow, S., Wolfrum, S., Shumer, D., Mimiaga, M.J. (2015). Mental Health of Transgender Youth in Care at an Adolescent Urban Community Health Center: A Matched Retrospective Cohort Study. Journal of Adolescent Health, 56, 274-279.

Reisner, S.L., Katz-Wise, S.L., Gordon, A.R., Corliss, H.L., \& Bryn Austin, S. (2016). Social epidemiology of depression and anxiety by gender identity. Journal of Adolescent Health, 59, 203-208.

Richards, C. and Barker, M. (2013). Sexuality and gender for mental health professionals: A practical guide. London: Sage.

Richards, C., Bouman, W.P., Seal, L., Barker, M.J., Nieder, T.O., T'Sjoen, G. (2016). Non-binary or genderqueer genders. International Review of Psychiatry, 28, 95-102. Rigby, L.W. \& Waite, S. (2007). Group therapy for self-esteem, using creative approaches and metaphor as clinical tools. Behavioral and Cognitive Psychotherapy, 35, 361-364.

Rosenberg, M. (1965). Society and the adolescent self-image. Princeton, NJ: Princeton University Press. 
Vocks, S., Stahn, C., Loenser, K., \& Legenbauer, T. (2009). Eating and body image disturbances in male-to-female and female-to-male transsexuals. Archives of Sexual Behavior, 38, 364-377.

Warren, J.C., Bryant Smalley, K., \& Barefoot, K.N. (2016). Psychological well-being among transgender and genderqueer individuals. International Journal of Transgenderism, $17(3+4)$,

Whiteford, H.A., Degenhardt, L., Rehm, J., Baxter, A.J., Ferrari, A.J., Erskine, H.E...., Vos, T.(2013). Global burden of disease attributable to mental and substance use disorders: findings from the Global Burden of Disease Study 2010. Lancet, 382, 1575-1586.

Wylie, K.R., Barrett, J., Besser, M., Bouman, W.P., Bridgeman, M., Clayton, A.,....., Ward D. (2014). Good practice guidelines for the assessment and treatment of adults with gender dysphoria. Sexual and Relationship Therapy, 29,154-214. Zigmond, A.S. \& Snaith, R.P. (1983). The hospital anxiety and depression scale. Acta Psychiatrica Scandinavica, 67, 361-370.

Zimet, G.D., Powels, S.S., Farley, G.K., Werkman, S., Berkoff, K.A. (1990).

Psychometric characteristics of the multidimensional scale of perceived social support. Journal of Personality Assessment, 1990; 55, 610-617. 
Table 1: Comparison between the number of transgender (TG) people (men, women and total) and cisgender controls regarding the existence or not of anxiety disorders $(n=1184)$

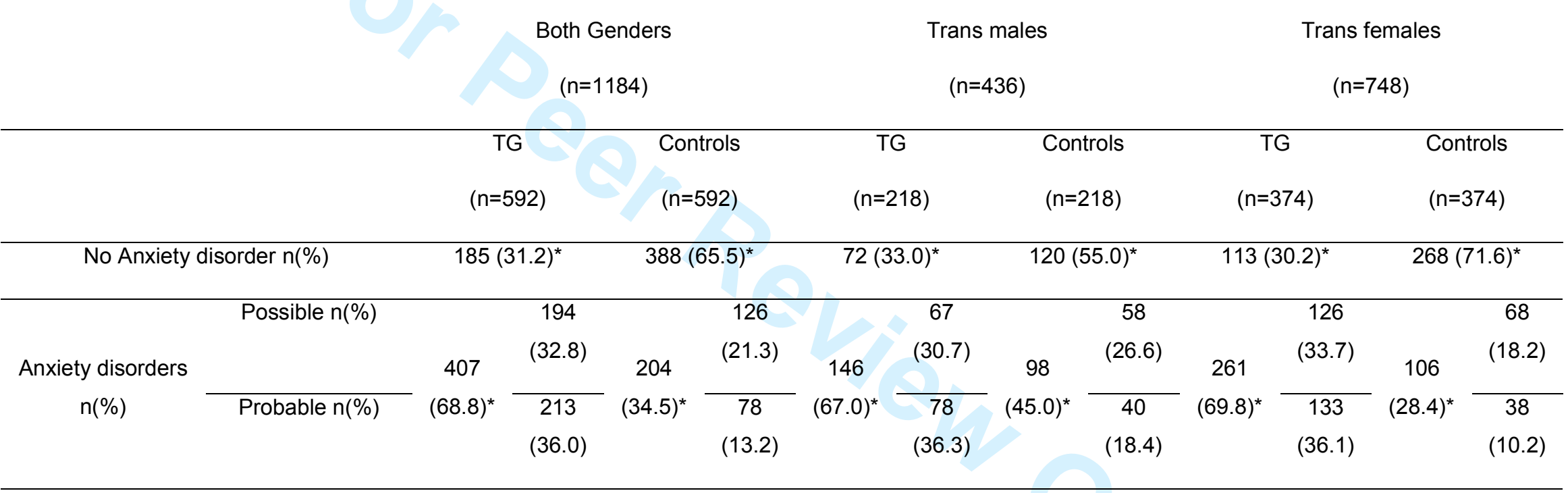


Table 2. Predictive role of age, gender, self-esteem, social support, interpersonal function and victimization in transgender people with possible and probable anxiety disorder (as one category) compared to transgender people with no anxiety disorder.

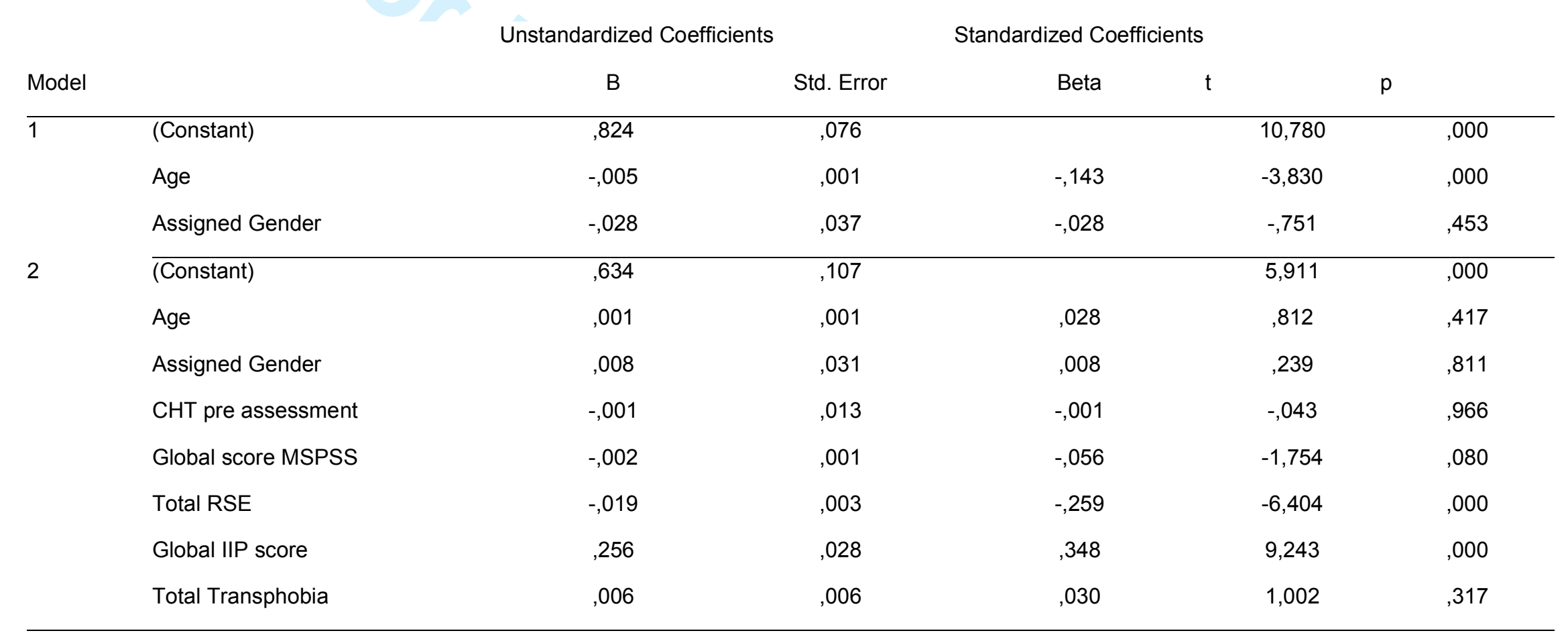

a. Dependent Variable: HADS score; * $p<0.05$ 
Table 3. Differences in anxiety symptomatology based on the HADS in transgender people on cross-sex hormone treatment (CHT) and those who are not on treatment $(n=899)$

\begin{tabular}{|c|c|c|c|c|c|c|}
\hline & \multicolumn{3}{|c|}{$\begin{array}{l}\text { Transgender people not on } \mathrm{CHT} \\
\qquad \mathrm{N}(\%)\end{array}$} & \multicolumn{3}{|c|}{$\begin{array}{l}\text { Transgender people on } \mathrm{CHT} \\
\qquad(\mathrm{N}(\%)\end{array}$} \\
\hline & $\begin{array}{c}\text { All } \\
(n=640)\end{array}$ & $\begin{array}{c}\text { Trans female } \\
\quad(n=393)\end{array}$ & $\begin{array}{c}\text { Trans male } \\
(\mathrm{n}=247)\end{array}$ & $\begin{array}{c}\text { All } \\
(n=259)\end{array}$ & $\begin{array}{c}\text { Trans female } \\
(n=179)\end{array}$ & $\begin{array}{c}\text { Trans male } \\
(\mathrm{n}=80)\end{array}$ \\
\hline No Anxiety disorder (Score 0-7) & $202(31.5)^{*}$ & $118(30.0)^{*}$ & $84(34.0)$ & $123(47.5)^{*}$ & $90(50.3)^{*}$ & $33(41.2)$ \\
\hline Possible or probable anxiety disorder (Score $\geq 8$ ) & $438(68.5)^{*}$ & $275(70.0)^{*}$ & $163(66.0)$ & $136(52.5)^{\star}$ & $89(49.7)^{*}$ & $47(58.8)$ \\
\hline
\end{tabular}

${ }^{*} p<0.05$ 